\section{Cartografia destinada à representação de dados gravimétricos}

Resumo: Neste trabalho será exposta a aplicação de técnicas de cartografia temática para a adequada representação de dados gravimétricos, através da explanação da aplicação do mapeamento de isolinhas. Os dados utilizados para este estudo fazem parte de um banco de dados gravimétricos provenientes do Instituto Astronômico e Geofísico (IAG) e Companhia Paranaense de Energia Elétrica (COPEL) do Paraná, totalizando aproximadamente 9000 estações, entre estes dados geodésicos, gravimétricos e topográficos. No processo de mapeamento, primeiramente foi avaliada a classificação do fenômeno em questão para definição dos intervalos verticais e análise da distribuição dos pontos. Posteriormente foi realizada a interpolação das isolinhas com auxílio do programa Surfer 8 e a representação final do mapa gravimétrico com base nos valores da gravidade absoluta o município de Curitiba.

\section{Cartography intended to data gravimetric representation}

Abstract: This work will be exposed to the application of thematic mapping techniques for proper representation of the gravity data, through explanation of the application isolines maps. The data used for this study are part of a database gravity from the Institute of Astronomy and Geophysics (IAG) and Companhia Paranaense de Energia Eletrica (Copel) Paraná, totaling approximately 9000 stations, among these geodetic data, gravity and topography. In the mapping process, first evaluated phenomenon classification in question to define the vertical intervals and points distribution analysis. Later interpolation was performed with the aid of the isolines Surfer 8 and the representation of the final gravimetric map based absolute gravity for the Curitiba city.
Vivian de Oliveira

Fernandes*

Engenheira Cartógrafa pela Universidade Federal do Paraná, Mestre em Engenharia Civil e Doutora em Engenharia Civil pela Universidade Federal de Santa Catarina, na área de Cadastro Técnico e Ordenamento Territorial com Doutorado Sanduiche na Universidade de Karlsruhe na Alemanha durante os anos de 2007 e 2008. Professora Adjunta I na Universidade Federal da Bahia (UFBA), é líder do Grupo de Pesquisa Análise e Representação de Informações Espaciais do Laboratório de Geomensura Theodoro Sampaio - LABGEO e Membro do Programa de Pós-Graduação em Engenharia Ambiental Urbana da POLI - UFBA

Palavras-chave:

Gravimetria; Isolinhas; Isarítmico

Key-Words: Gravimetry; Isolines; Isaritmic. 


\section{Introdução}

Desde a década de 70, a Região Metropolitana de Curitiba e arredores foram objeto de levantamentos constantes, revelando uma malha de dados pouco consistente e com vários vazios no interior do Estado do Paraná. As maiorias dos dados existentes encontram-se nas proximidades das rodovias do Estado. Com base em Fernandes (2003), deu-se a construção de um banco de dados georreferenciados para dados topográficos e gravimétricos do Estado do Paraná. A partir deste banco de dados foi procedida a representação espacial por meio de técnicas de cartografia temática. No entanto, pretende-se com este trabalho fazer uma explanação a respeito de conceitos de gravimetria, rede gravimétrica e técnicas de mapeamento isarítimico por isolinhas.

\section{Referencial Teórico}

\section{Gravimetria}

De acordo com Torge (2001) por Gravimetria (grave= peso, metria= medição) entende-se "medição da gravidade", a medição da magnitude do vetor da aceleração da gravidade g. 0 estudo do campo gravítico, através da sua função potencial, necessita do conhecimento de certas quantidades desse mesmo campo, nomeadamente, as componentes do vetor gravidade (gradiente da função potencial). A quantidade do campo gravítico mais importante para a Geodésia é o geóide (superfície equipotencial de referência altimétrica), a qual se relaciona diretamente com 0 valor da gravidade através da Fórmula de Stokes. Diferentes densidades de massa geram diferentes valores de atração gravitacional. Por isso, conhecendo-se com rigor os valores do campo gravítico (efeito), podem-se determinar modelos rigorosos de distribuição das massas (causa).

A gravimetria só fornece valores de gravidade e sua distribuição é obtida em função dos levantamentos com gravímetro.

a) Possibilitar, juntamente com outras grandezas relacionáveis, a determinação do campo gravítico e a conseqüente e adequada modelação da superfície do geóide.

b) Contribuir para estudos de Geofísica pois a geofísica é ampla e envolve outros parâmetros não só gravimétricos, conseqüente, conhecimento da estrutura e variação da densidade da crosta terrestre.

O objetivo da gravimetria é determinar o campo gravítico da Terra, ou de qualquer outro corpo celeste, como função da posição e do tempo através da medição do valor da gravidade e do seu gradiente na superfície do corpo ou nas suas imediações (Torge, 2001).

A informação gravimétrica faz parte do arcabouço de dados integrantes do Sistema Geodésico Brasileiro e reveste-se de primordial importância em diversas áreas das ciências da Terra, como por exemplo, na Geodésia (estudo da forma - geóide - e dimensões da Terra), na geologia (investigação de estruturas geológicas e prospecção mineral.

Em 1956, o IBGE iniciou um programa visando o estabelecimento do datum (sistema geodésico de referência) horizontal para o Brasil. Durante o projeto, foram determinadas mais de 2.000 estações gravimétricas em torno do vértice Chuá, ponto origem, situado em Minas Gerais. Com o término dos trabalhos, o IBGE executou diversos outros levantamentos gravimétricos em conjunto com universidades e institutos de pesquisa.

Contudo, a gravimetria somente adquiriu um caráter sistemático a partir de 1990, quando

Geografia Ensino \& Pesquisa, v. 17, n.1 p. 81 -92 jan./abr. 2013

Cartografia destinada à representação de dados gravimétricos - IBGE estabeleceu estações gravimétricas visando recobrir os grandes vazios de informação de aceleração da gravidade que existem, especialmente nas regiões norte, centro-oeste e nordeste do Brasil. Desde então, mais de 26.000 estações foram estabelecidas nestas regiões.

Com a tecnologia GPS, a determinação do geóide reveste-se de grande importância no posicionamento vertical. Apesar do GPS ser um sistema tri-dimensional, as altitudes fornecidas por ele estão em um sistema altimétrico diferente daquele em que estão as obtidas pelos métodos 
clássicos de nivelamento (geométrico, trigonométrico e barométrico). Isso faz com que as altitudes GPS não possam ser diretamente comparadas com as altitudes e mapas fornecidos pelo IBGE e outros institutos brasileiros. O mapa geoidal representa a conversão entre os dois sistemas de altitude. Para que essa tecnologia GPS seja plenamente aproveitada, proporcionando economia de tempo e recursos, necessita-se de um mapa geoidal cada vez mais preciso, já que a precisão da transformação é função da precisão na determinação do geóide.

A determinação de altitudes científicas (ortométricas, normais, etc), requer de informação gravimétrica para sua determinação. Assim sendo, desde 2006 campanhas de levantamentos gravimétricos vem sendo executadas sobre as linhas principais de nivelamento, com a finalidade de auxiliar no cálculo destas altitudes e facilitar a conexão da Rede Altimétrica Brasileira com as Redes dos países vizinhos.

\section{Mapeamento de Isolinhas - Mapeamento Isarítmico}

\section{Conceitos fundamentais}

O mapeamento de isolinhas é uma representação gráfica planimétrica de um volume tridimensional, que através de símbolos lineares representa a superfície de um volume tridimensional, gerando uma superfície. Esta superfície é representada através de um volume formado pelas coordenadas $x, y, z$.

Um mapa isarítmico é a representação plana através de isolinhas de uma superfície tridimensional, que pode ser uma superfície real, como o relevo, ou uma superfície abstrata ou conceitual. Uma superfície conceitual é uma distribuição geográfica de valores de dados, ou seja, dados numéricos como temperatura ou densidade demográfica, coletados para localizações geográficas específicas. A técnica de mapeamento isarítmico só pode ser empregada caso exista, ou possa ser abstraída, esta superfície tridimensional contínua (DENT, 1999).

Mapas isarítmicos podem ser classificados em isométricos ou isopléticos, de acordo com a natureza dos dados a partir dos quais foram gerados. Nos mapas isométricos, os dados foram coletados para localizações pontuais específicas, os pontos de controle, como dados de temperatura em estações meteorológicas. Nos isopléticos, os dados referem-se a unidades de enumeração de áreas geográficas, como densidade demográfica ou taxa de produção agrícola (SLOCUM, 1999).

No caso dos mapas isométricos, os valores do fenômeno nos pontos de controle podem ser divididos em valores reais e derivados. Valores reais são como temperatura, precipitação pluviométrica e elevação. Tais valores são obtidos por levantamentos de campo ou sensoriamento remoto. Valores derivados podem ser medidas estatísticas como médias e medidas de dispersão ou ainda proporções e razões (DENT, 1999).

O método para construção dos mapas isarítmicos pode ser visualizado na Figura 1. Inicialmente, são escolhidas as posições horizontais para os pontos de controle. A seguir, são atribuídos os valores observados a cada um destes pontos. Os valores para os demais pontos do mapa são então estimados através de um processo de interpolação. A superfície formada é suavizada, de modo a formar uma superfície contínua. As isolinhas são traços planimétricos das interseções de planos hipotéticos com esta superfície ondulada tridimensional (DENT, 1999).

No mapeamento isométrico, o posicionamento horizontal das amostras é determinado pela posição dos instrumentos de medição ou dos dados disponíveis ou escolhidos em fotos aéreas ou imagens de satélite. Problemas derivam da não uniformidade da distribuição destes pontos, que gera diferentes precisões na interpolação. Nos casos em que 0 cartógrafo não possui controle sobre o padrão de distribuição dos pontos de controle, é preferível utilizar uma grade triangular (DENT, 1999). O uso de uma rede irregular de triângulos (TIN - "Triangular Irregular Network") é bastante comum na representação do relevo. Esta rede é construída através da ligação de pontos com valores conhecidos (pontos de controle) formando uma triangulação de Delaunay. A triangulação permite que sejam utilizados pontos de controle irregularmente distribuídos e a densidade

Geografia Ensino \& Pesquisa, v. 17, n.1 p. 81 - 92 jan./abr. 2013

Fernandes, V. O. 
dos pontos pode ser ajustada pelo grau de variação da superfície. Áreas com pequenas variações podem ser representadas por poucos triângulos, enquanto um maior número é necessário para áreas com variações mais freqüentes (BURROUGH; MCDONNELL, 1998). A Figura 2 mostra uma rede triangular irregular.

Figura 1- Construção do mapa isarítmico

\section{Representação proporcional ao valor do fenômeno.}

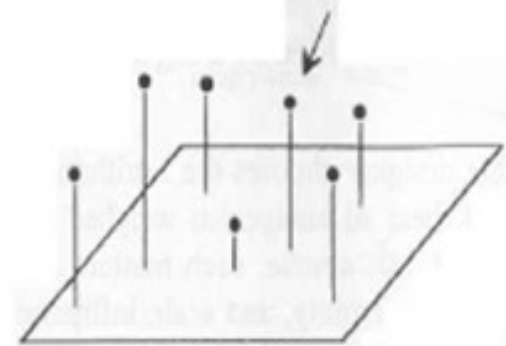

3. Planos hipotéticos atravessam o volume.
2. Superficie obtida pela interpolação dos valores.
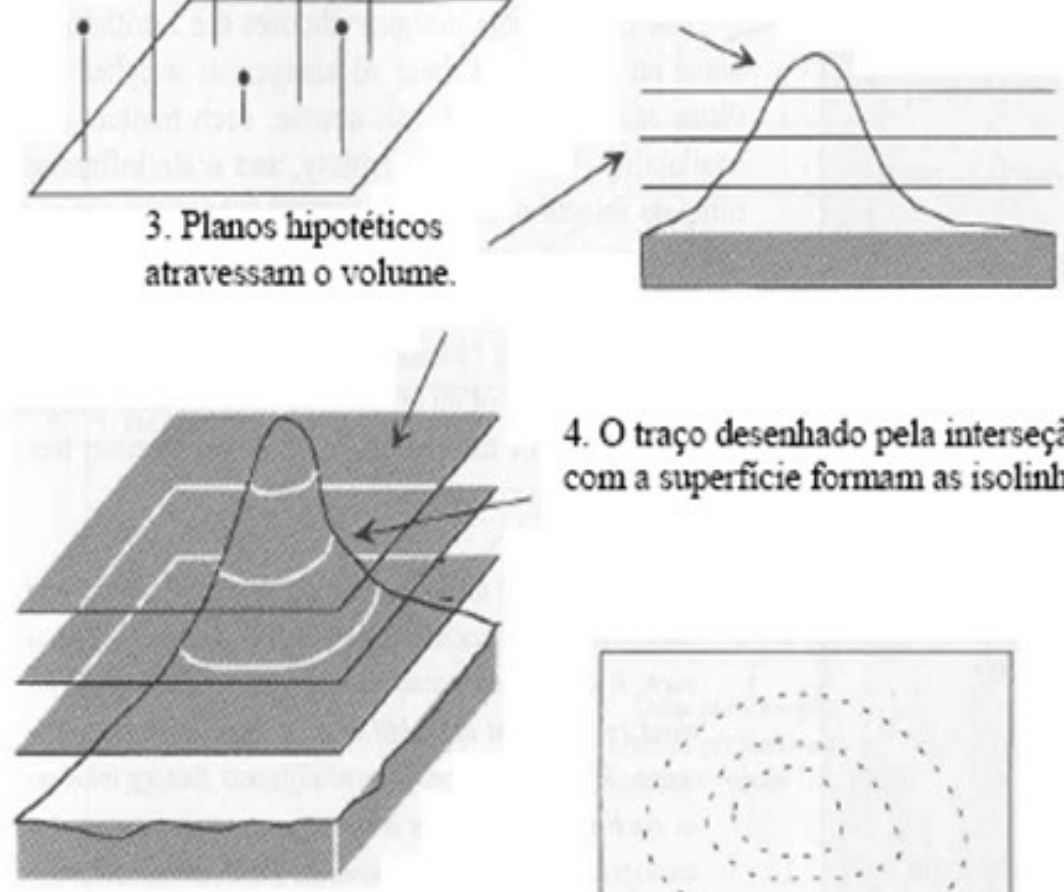

4. O traço desenhado pela interseção dos planos com a superficie formam as isolinhas.

5. O desenho planimétrico dos traços

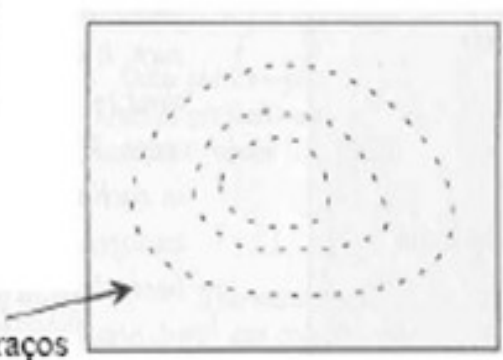
formam o mapa isaritmico.

Fonte: Dent (1999)

Figura 2 - Rede Triangular Irregular

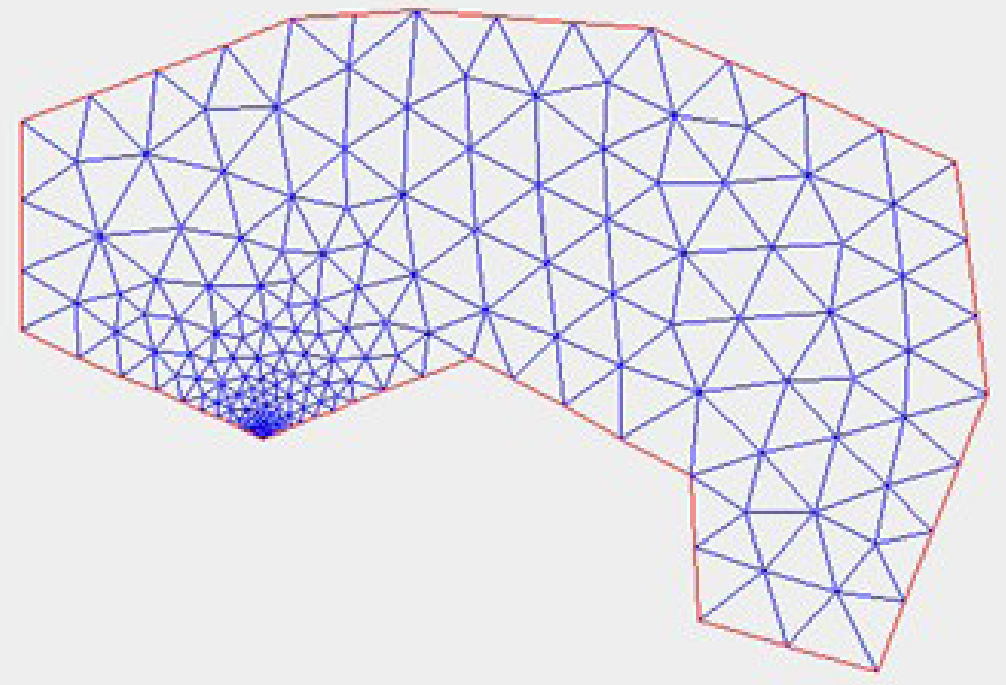


Já os mapas isopléticos são gerados a partir de dados que ocorrem sobre as unidades de área. Podem ser representados valores que envolvem áreas direta ou indiretamente, como densidade populacional ou produção agrícola por hectare. Valores totais devem ser transformados em razões de área antes do mapeamento (DENT, 1999).

No mapeamento isoplético, a localização dos pontos de controle é um procedimento mais trabalhoso. Um ponto é selecionado dentro da unidade de enumeração e a ele é atribuído um valor que representa o valor médio da área considerada, ou seja, uma razão ou proporção que envolve a medida da área. A localização do ponto de controle dentro da área afetará sua acurácia e aparência, que deve refletir os atributos espaciais da distribuição. Caso esta distribuição ocorra de modo uniforme, o centro geográfico da unidade de área pode ser utilizado. De forma geral, DENT (1999) recomenda que se utilize o centro de gravidade da distribuição (Figura 3).

Figura 3 - Pontos de controle para mapas isopléticos

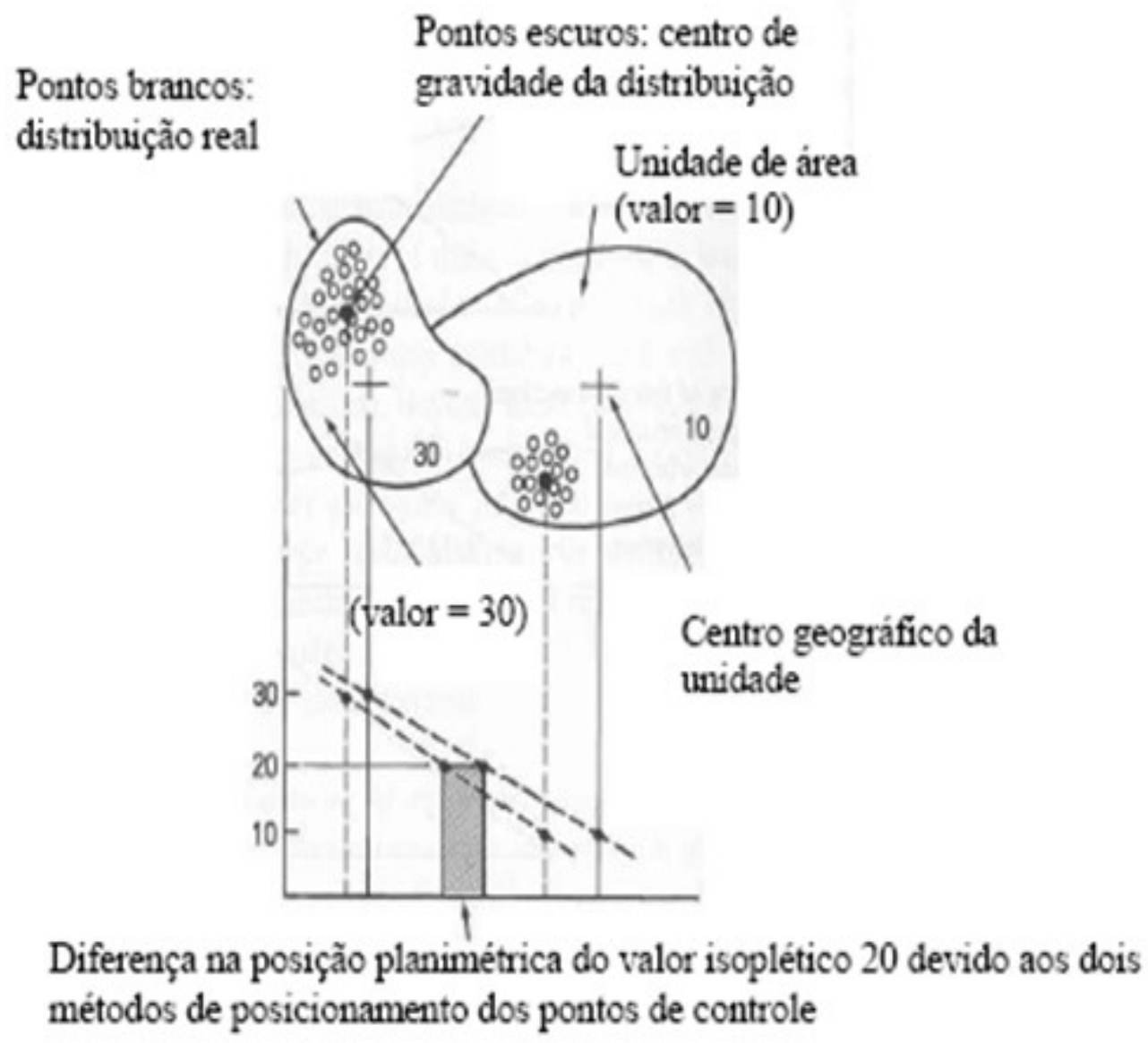

Fonte: DENT (1999)

Após a etapa de seleção da posição dos pontos de controle, a geração do mapa isoplético é idêntica à do mapa isométrico, ou seja, os valores destes pontos são interpolados para formar uma superfície que será interceptada por planos, como mostrado na Figura 1.

As posições verticais dos planos hipotéticos são selecionadas a partir de uma origem (datum) adotada para o mapa específico. A faixa dos valores representados determina o valor do datum, normalmente zero. Cada plano possui um valor numérico que indica sua distância ao datum, $\mathrm{e}$ este será o valor da respectiva isolinha. Como os planos são paralelos ao datum, a isolinha possui 0 mesmo valor em toda a sua extensão. Os planos horizontais devem estar espaçados uniformemente, de modo a permitir análises derivadas de seu espaçamento horizontal (Figura 4). A seleção do intervalo vertical utilizado depende da distribuição do fenômeno na região e deve ser feita de modo a evitar grandes concentrações de isolinhas, ou áreas com grandes vazios (DENT, 1999).

Geografia Ensino \& Pesquisa, v. 17, n.1 p. 81 - 92 jan./abr. 2013

Fernandes, V. $\mathrm{O}$.

ISSN 2236-4994 
Figura 4 - Espaçamento uniforme dos planos horizontais

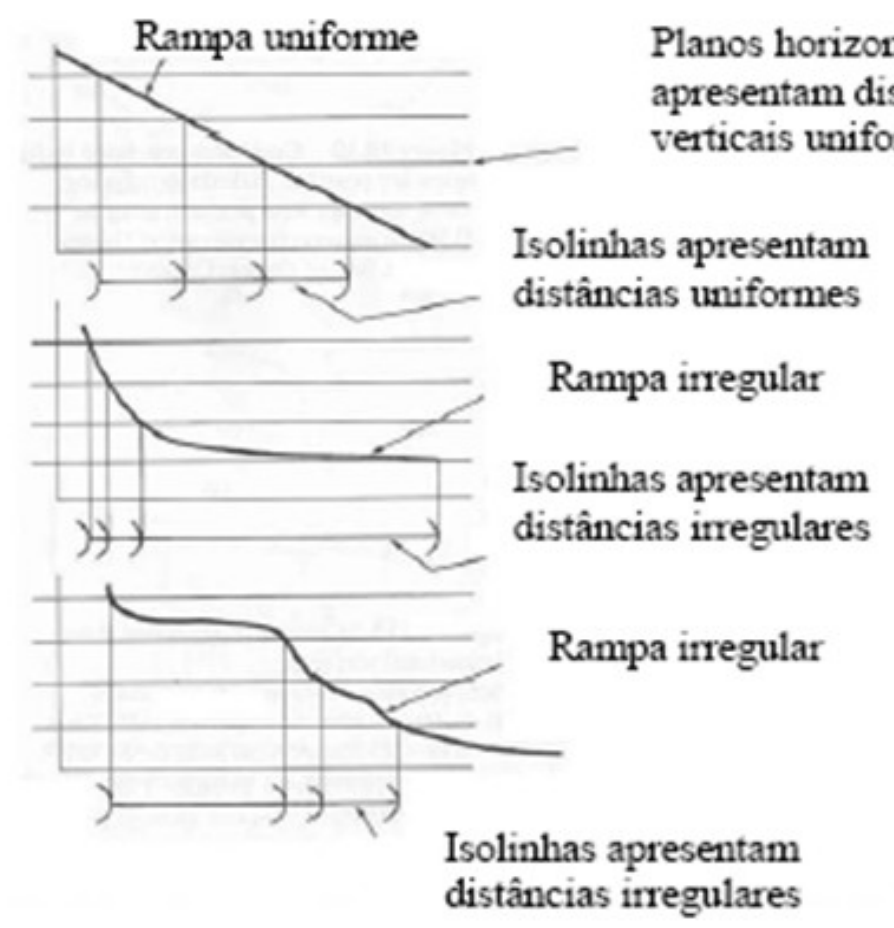

Fonte: Dent (1999)

A posição das isolinhas é determinada por métodos de interpolação, que são procedimentos para calcular o valor de atributos em locais em que estes não estão disponíveis, a partir das medidas disponíveis (BURROUGH; MCDONNELL, 1998). A escolha do método de interpolação depende do conhecimento do cartógrafo sobre a distribuição do fenômeno na área a ser mapeada. $\mathrm{Na}$ triangulação, é construído um conjunto de triângulos que possuem como vértices os pontos de controle. Os valores ao longo das arestas destes triângulos são interpolados. No método do inverso da distância, é criada uma grade de pontos igualmente espaçados e posicionada sobre os pontos de controle. $O$ valor de cada ponto da grade é estimado como uma função do inverso da distância aos pontos de controle. A seguir são interpolados os valores entre os pontos da grade. 0 "kriging" é um método semelhante que considera não apenas a distância até os pontos de controle mas também a autocorrelação espacial entre os dados, tanto entre os pontos da grade e os pontos de controle quanto dos pontos de controle entre si (SLOCUM, 1999).

Não existem regras universais para o posicionamento das isolinhas, mas algumas heurísticas podem ser empregadas. Valores de isolinha são mais reveladores quando coincidem com mudanças abruptas na declividade. Toda a região deve ser considerada, e o intervalo escolhido deve ser o que acomoda melhor os lugares de mudanças rápidas e fornece detalhes suficientes para mostrar a forma da superfície.

Neste tipo de mapa, as isolinhas transmitem informação através de sua magnitude, espaçamento e orientação (DENT, 1999).

Algumas recomendações no projeto gráfico de mapas isarítmicos são destacadas por DENT

Geografia Ensino \& Pesquisa, v. 17, n.1 p. $81-92$ jan./abr. 2013

Cartografia destinada à representação de dados gravimétricos (1999). As isolinhas devem ser dominantes no mapa. Os rótulos destas devem ser posicionados em intervalos ao longo das linhas, mas não intervalos muito pequenos, pois isso interfere na visualização da superfície tridimensional. Deve-se tomar cuidado com a orientação do texto na direção da leitura, e nunca de cabeça para baixo. DENT (1999) não considera apropriado o uso de sombreamento ou cores uniformes entre as isolinhas pois alega que isso pode levar o usuário a entender a superfície como formada por degraus, o que não deve ser a intenção do cartógrafo. KEATES (1988) ressalta que, por serem as áreas elementos visualmente dominantes sobre as linhas, estas cores hipsométricas podem ser utilizadas apenas em pequenas escalas. 


\section{Considerações sobre o projeto de mapeamento}

Do banco de dados com aproximadamente 9000 estações cadastradas, foram selecionadas 100 estações pertencentes à área de estudo dentro do município de Curitiba/PR. A área escolhida foi a cidade de Curitiba, e foram selecionadas coordenadas que estavam entre $-25^{\circ}$ e $-24^{\circ}$ de latitude e $-48^{\circ}$ e $-51^{\circ}$ de longitude. Foram separadas apenas as informações que continham dados sobre a latitude, longitude e gravidade absoluta no ponto.

Na tabela 1 a seguir é apresentada apenas parte dos dados utilizados para representação:

Tabela 1 - Parte dos dados que foram utilizados

\begin{tabular}{|c|c|c|}
\hline Latitude $\left({ }^{\circ}\right)$ & Longitude $\left(^{\circ}\right)$ & Gravidade (mGal) \\
\hline$-25,37850002$ & $-49,1558$ & 978763,4 \\
\hline$-25,36709998$ & $-49,12810004$ & 978760,3 \\
\hline$-25,35679998$ & $-49,1039$ & 978762,5 \\
\hline$-25,35240002$ & $-49,07029996$ & 978764,4 \\
\hline$-25,34680003$ & $-49,04830004$ & 978774,8 \\
\hline$-25,34049996$ & $-49,02170002$ & 978774,8 \\
\hline$-25,30819999$ & $-49,00079997$ & 978778,1 \\
\hline$-25,42629998$ & $-49,2242$ & 978765 \\
\hline$-25,40659998$ & $-49,21779997$ & 978766,2 \\
\hline$-25,38849998$ & $-49,20530004$ & 978760 \\
\hline$-25,36460003$ & $-49,18529996$ & 978754 \\
\hline$-25,35020001$ & $-49,16359998$ & 978763,2 \\
\hline$-25,328$ & $-49,15919995$ & 978757,9 \\
\hline$-25,31300004$ & $-49,14609995$ & 978742,7 \\
\hline$-25,2955$ & $-49,15309997$ & 978741,9 \\
\hline$-25,2782$ & $-49,14000004$ & 978745,9 \\
\hline$-25 \% 5.50004$ & $-491346,9996$ & 978759.3 \\
\hline
\end{tabular}

\section{Classificação do fenômeno}

Para representação de dados gravimétricos na forma de isolinhas é necessário a definição dos intervalos verticais.

Para definição dos intervalos verticais construiu-se o histograma com os dados e atribuiu-se o intervalo ideal de 0,1 mGal. Com esta equidistância é possível representar as maiorias das variações dentro das amostras. 0 intervalo deve ser definido de forma que esteja compatível à amostragem.

Figura 5- Histograma para eqüidistância de 0,1mGal

\section{Histograma}

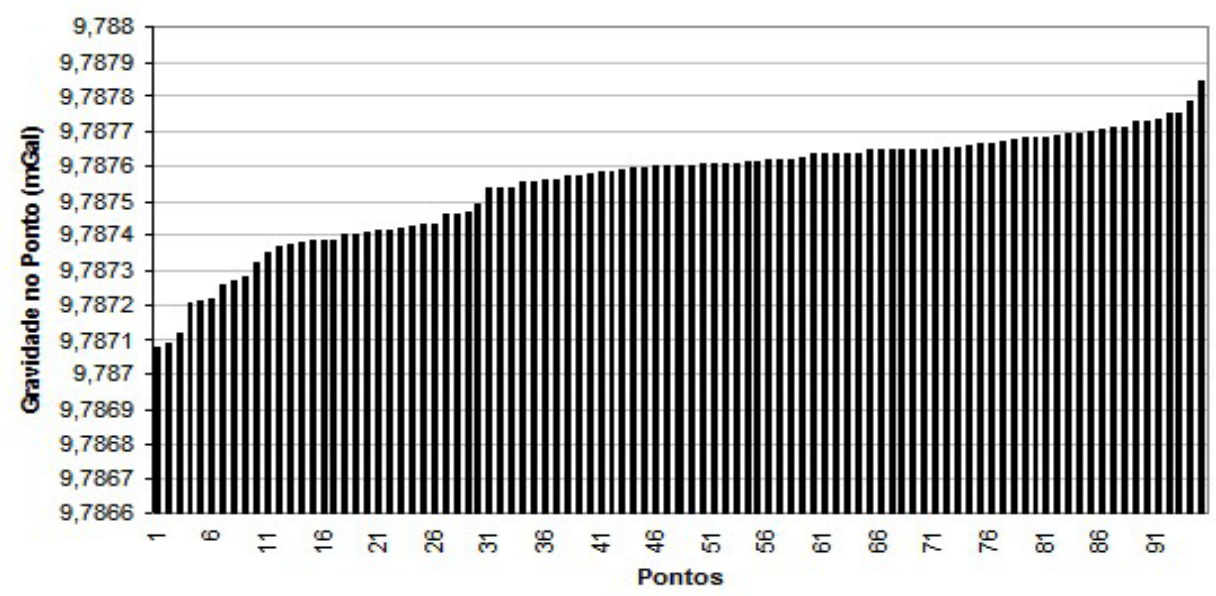

Geografia Ensino \& Pesquisa, v. 17, n.1 p. 81 - 92 jan./abr. 2013

Fernandes, V. 0 . 


\section{Interpolação - Posicionamento das isolinhas}

Para interpolação dos dados foi utilizado o Programa Surfer e o método de interpolação utilizado foi o inverso da distância. Este interpolador utiliza um interpolador de média ponderada e que pode ser exato ou suavisante em relação à concordância com os pontos originais de observação.

Uma interpolação ideal é aquela no qual a superfície interpolada ajusta-se aos dados a um determinado nível de precisão é fiel aos dados dentro de um limite arbitrário definido pelo usuário. A superfície interpolada é contínua e suave em todos os locais.

\section{Distribuição dos pontos observados}

Através da figura 6 pode-se visualizar a distribuição dos dados. Pontos os quais foram observados através das avenidas e rodovias na cidade de Curitiba/PR.

Falta apresentar o Mapa de Pontos da área estudada com adas.

Figura 6- Distribuição dos pontos observados na cidade de Curitiba

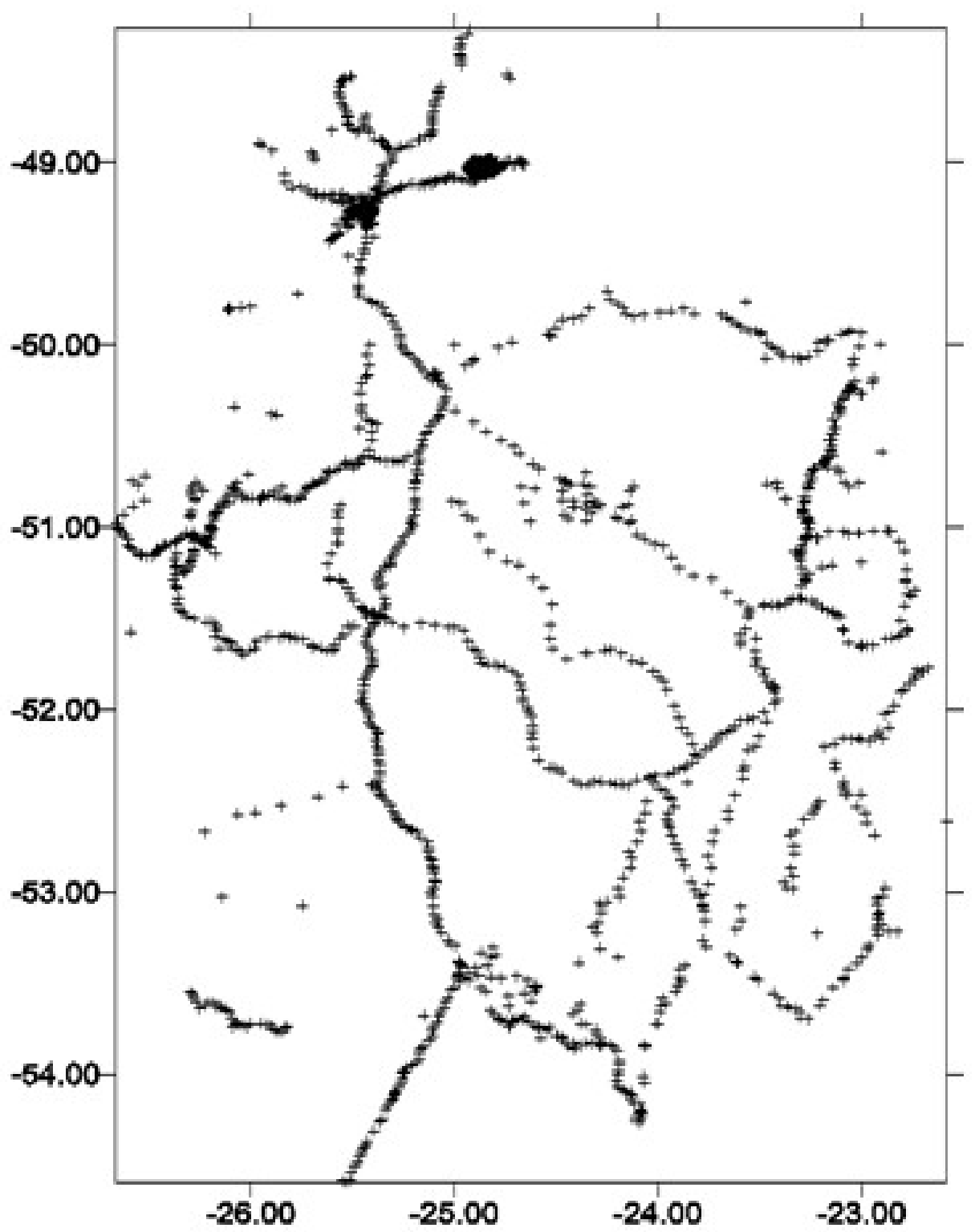




\section{Resultados}

A figura 7 apresenta um resultado preliminar dado pelo Software Surfer 8 para Windows de propriedade do Laboratório de Geomensura da Universidade Federal da Bahia que possui poucos recursos de edição. Mas tem como facilidade a realização de interpolações.

Figura 7- Resultado preliminar após a interpolação dado pelo Software Surfer

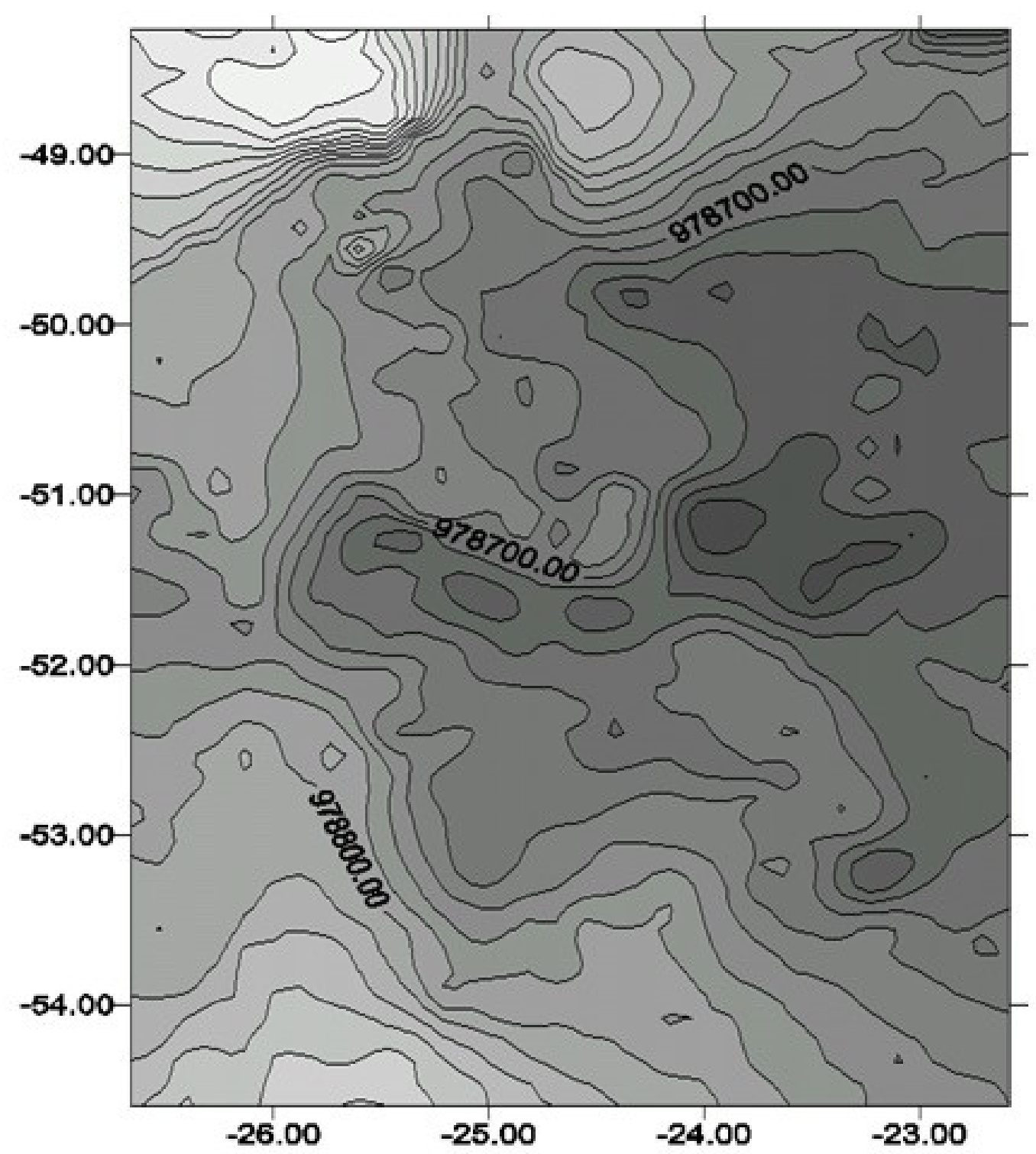

A seguir é apresentado o resultado final após a edição e confecção do Layout, através da figura 8. 
Figura 8- Mapa gravimétrico com base na gravidade absoluta da Cidade de Curitiba/PR

\section{MAPA GRAVIMÉTRICO CIDADE DE CURITIBAJPR (GRAVIDADE ABSOLUTA)}

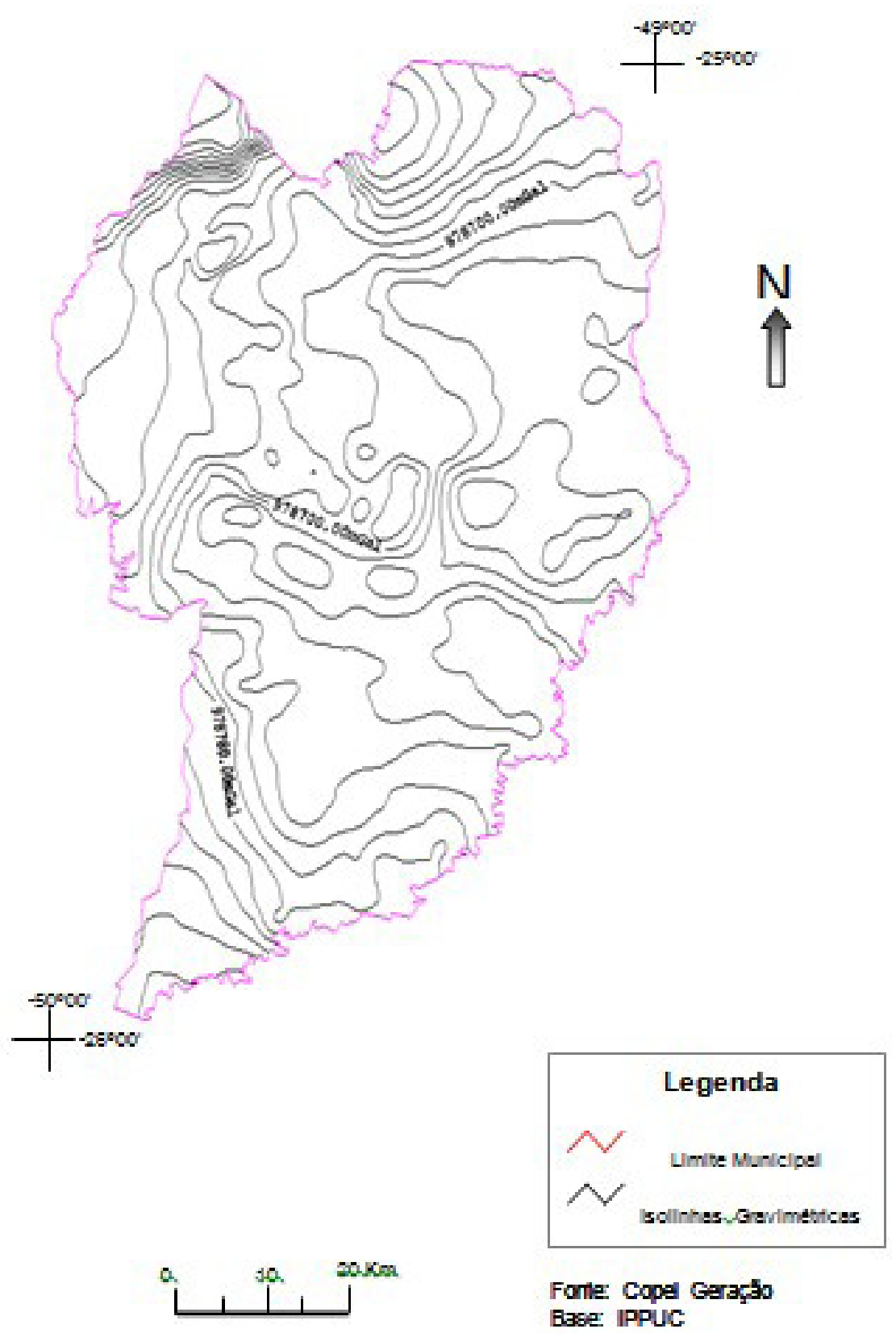

\section{Conclusões}

Ultimamente com o crescimento de ferramentas que possibilitam a construção de mapas,

Geografia Ensino \& Pesquisa, v. 17, n.1 p. 81 -92 jan./abr. 2013

Cartografia destinada à representação de dados gravimétricos fazem com que os usuários e pesquisadores que trabalham com dados geográficos georreferenciados desconheçam os processos para a construção de mapas temáticos, principalmente com toda a automatização dos processos. 0 presente trabalho procurou focar no processo de mapeamento de isolinhas, tendo o tema os dados gravimétricos de modo a construir uma carta o mapa geoidal é um mapa obtido por interpolação, que por sinal trata-se de um procedimento matemático e não geofísico geoidal. Verificou-se que apesar do adensamento dos dados do referido banco, estes dados concentram-se ao longo das rodovias, o que é ocasionado pela dificuldade de acesso para 
realização de levantamentos ideais por dificuldade física para ocupação.0 posicionamento das estações devem obdecer uma distribuição tal que os valores a serem interpolados ajustem-se a uma superfície de distribuição regular

\section{Referências Bibliográficas}

FERNANDES, V. de O. Construção de um Banco de Dados Georeferenciados para Dados Topográficos e Gravimétricos do Estado do Paraná. In: III Colóquio Brasileiro de Ciências Geodésicas, 2003, Curitiba. Anais do III Colóquio Brasileiro de Ciências Geodésicas. Curitiba: UFPR, 2003.

DENT, B. D. Cartography Thematic Map Design. 5th. Edition. WCB/McGraw-Hill. 1999

SLOCUM, T. A. Thematic Cartography and Visualization. New Jersey: Prentice-Hall, 1999.

BURROUGH, P. A.; MCDONNELL, R. A. Principles of geographical information systems: spatial information systems and geostatistics. New York: Oxford University Press, 1998.

Wolfgang Torge. Geodesy: an introduction. Edition, 3, illustrated. Publisher, Walter de Gruyter, 2001.

KEATES, J.S. Cartographic design and production. $2^{2}$ ed. New York: Longman Scientific and Techinical, 1988, 266p.

\section{Correspondência:}

Vivian de Oliveira Fernandes- Universidade Federal da Bahia, Escola Politécnica. Aristides Novis 2, Federação, 40210-630 - Salvador, BA - Brasil

E-mail: vivian.fernandes@ufba.br

Recebido em 05 de novembro de 2012.

Revisado pelo autor em 03 de dezembro de 2012.

Aceito para publicação em 21 de janeiro de 2013. 